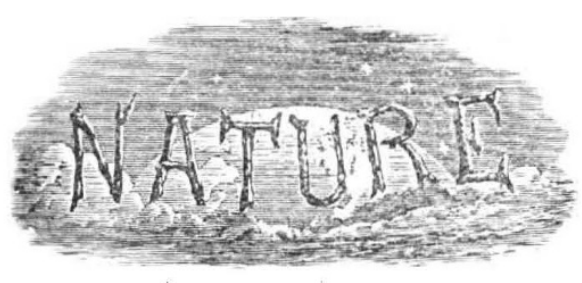

SATURDAY, JULY I5, 1922.

CONTENTS.

Specialisation in Universities

PAGE

More Light on the Bantu Languages. By Miss A.

Werner

Chemistry and Medicine. By Prof. George Barger,

F.R.S.

The Hegelian Method and Modern Science. By

H. W. C.

Joaps and Proteins

Commercial Metallurgy. By H. C. H. C.

Scientific Activities in the United States: A Bio-

logist's View

Our Bookshelf

Letters to the Editor:-

Interspecific Sterility.-Dr. W. Bateson, F.R.S.

Geology and the Nebular Theory.--Prof. J. Joly,

F.R.S. ; W. B. Wright

Wegener's Displacement 'Theory.-Philip Lake

Opalescence Phenomena in Liquid Mixtures. - Prof.

C. V. Raman

Transcription of Russian Names. - Maj.-Gen. Lord Edward Geichen, K.C.V.O.

The Influence of Science--Sir G. Greenhill, F. R.S., The Editor

Science and Education at South Kensington, illlus. trated.) By T. L1. Humberstone

Dark Nebulæ. By Prof. H. N. Russell

The Corrosion of Ferrous Metals. By J. N. F

Obituary :-

Ernest Solvay. By John I. Watt

The Hon. V. A. H. H. Onslow

Dr. A. R. Willis, By A. R. R. and G. W. C. K.

Current Topics and Events .

Our Astronomical Column.

Research Items

Annual Visitation of the National Physical Laboratory

Agricultural Research in Great Britain

The Magnetic Work of the Carnegie Institution.

By Dr. C. Chree, F.R.S.

New Social Coleoptera. By Dr. A. D. Imms :

Spectroscopic Studies of Stellar Velocities. By Dr.

William J. S. Lockyer

Geology of Antarctic Lands. By G. A. J. C.

Durability of Optical Glass. By Dr. James Weir French

Volcanic Activity in Nigeria

University and Educational Intelligence.

Calendar of Industrial Pioneers .

Societies and Academies

Official Publications Received

Diary of Societies

Editorial and Publishing Ofices:

MACMILLAN \& CO., LTD.

ST. MARTIN'S STREET, LONDON, W.C.2.

Advertisements and business letters should be addressed to the Publishers.

Editorial communications to the Editor.

Telegraphic Address: PHUSIS, LONDON.

Telephone Number: GERRARD 8830.

\section{Specialisation in Universities.}

$\mathrm{T}^{\mathrm{T}}$ is not the function of a university to make 1 provision for teaching all the sciences; still less is it the function to confine its work to one narrow branch of specialised study. In one case, apart from the difficulties inherent in such an aggregation, the financial cost would be prohibitive ; in the other, a limitation of such a nature would be wholly alien to the modern conception of a university, where, in place of the breadth and proportion of view which comes from the attrition of minds engaged in diverse studies and pursuits, would be found the narrowness and exclusiveness of intellectual segregation. We may therefore dismiss one extreme as impracticable and the other as undesirable.

The universities of to-day have many subjects of study in common. Happily the freedom to develop according to their own individualities, which has hitherto been their lot, has resulted in certain characteristic differences. It is devoutly to be hoped they may not lose these distinctions. The studies common to all universities form a broad humanistic and scientific sfoundation which is the basis of the intellectual life of the university. Superimposed upon this are the more highly specialised studies, which may in some scases cover a very narrow field, but not seldom form a department in the university linked up in innumerable ways with one or more branches of industrial or commercial life outside. This development has been gradual and, in general, continuous, and it is due to a variety of causes of which probably the two most effective may be defined as historical and regional or environmental. As matters now stand, some studies have already been specialised in certain of the universities and, until quite recently, largely by a process of natural development. To overlook or to underestimate the importance and bearing of this fact would be a mistake.

If the universities were self-supporting or mainly so, it is unlikely that the present system, which on the whole has worked well, would be challenged-it may yet prove to be the best in any circumstances -but since they are not self-supporting, and since they are coming to rely more and more upon assistance from State funds and local rates, they need not be surprised if a time comes when a critical eye is turned upon their activities. Such a time is with us now. The cry for economy, the reduction in the Government grant, the threat of lean years ahead, apart from other considerations, have brought to the forefront the question of the overlapping of university studies, and the possibility of better co-ordination and co-operation of the universities in the future, especially with regard to

NO. 275 O, VOL. I IO] 
the ever-increasing expansion and development of technology and applied science.

With regard to the question of overlapping it should be remarked that at the recent conference in London of the Universities of Great Britain and Ireland, no statement was more generally applauded than that of Prof. Ripper, of Sheffield, who reminded the conference and the public that at present there was no unnecessary overlapping in university studies. Overlapping there may be, but whether this is unnecessary and wasteful is quite another question and one which cannot be answered by mere statistics. This is where co-operation would be most useful both now and in the future. The Minister of Education was on sound lines when, in addressing the conference, he advised the universities to take counsel with one another and husband their resources. Possible wastefulness due to overlapping ought not to be disregarded at any time and most certainly not at a time of financial stringency.

If, for example, each university were to attempt to cover all the main branches of technology, though perhaps the demand for university-trained technologists in a particular field did not reach a score annually, then disappointment and ineffective work must be the result. Obviously where the demand for trained technologists in a particular subject is limited to a comparatively small number, there is distinctly a case for specialising the study in one university. How far universities would attempt to compete with one another in such cases it is difficult to say. But it is worth recalling that, at the conference to which we have already alluded, Mr. Fisher directed attention to the public-spirited action of the University of Ieeds a few years ago when glass technology was proposed as a subject for university research. It appears that either Leeds or Sheffield might have been the seat of the new department, but after a conference Leeds agreed to the new work being centred in Sheffield on the ground that the Yorkshire glass industry as a whole was more accessible from there than from Leeds. The method of procedure by conference should be noted.

Cases such as this are obviously cases for specialisation and are perhaps not difficult to settle. It would seem that the limited demand points to concentration and the "regional pull" to the particular university. On the other hand such highly specialised subjects as technical optics, oceanography, hydro-electrics cannot be said to have so localised a regional pull, nor Chinese, Assyriology, and a host of others. Again, departments of study connected with agriculture, forestry, leather industries, dyeing, textile industries, metallurgy, fuel and coal gas industries are already established in one or more of our universities. If, as is more than likely, any further specialisation of studies is to be made in these departments, especially if it involves considerable expense, obviously there would arise an occasion for co-operation among the various universities interested with the view of suitable distribution of the work.

So far we have been considering the subject of specialisation in universities from the point of view either of the more highly specialised studies or of technology or applied science generally, and have indicated our opinion that in these fields there will be ample scope and real necessity for co-ordination and co-operation. But there is another aspect of the problem which is apt to be overlooked or even in danger of being confused with the one just considered. It has relation to those basic humanistic and scientific studies which are the foundations of the intellectual life of the universities. Among them are included such subjects as the classics, English, history on one side, and mathematics, physics, chemistry on the other. They are found in all our universities, and rightly so, and so long as the university is conceived as " a spirit, a principle of life and energy, an influence . . . caring for the spirit and mind of man, regardless of considerations of utility," so long will they remain there. While, therefore, it is not disputed that the more fundamental of them should be taught in every university, it may be urged in the interests of a specious economy that the prosecution of research in them should be specialised in certain universities. This, we believe, would be a most dangerous principle to adopt, and would be quite contrary to the true spirit of the university. The effect upon the teaching would be little short of disastrous. In its Report of I92I the University Grants Committee is clear that "sufficient leisure to pursue research is as essential as adequate remuneration," and that "no institution claiming university rank can rest content while it fails to provide opportunities for the advancement of knowledge, nor can junior teachers hope to rise in their profession or indeed carry out their teaching duties efficiently unless such opportunities are open to them." This extract amply confirms the general opinion expressed at the second Congress of the Universities of the Empire, I $92 \mathrm{I}$, regarding the great importance and value of research to a university teacher. Without research behind him a university teacher fails in the freshness, mastery, and inspiration required of a good teacher of university students. Whenever such fundamental studies are found in a university some opportunities for research in them should be provided. This may mean overlapping, but it is not overlapping involving wastefulness. 
The case is almost equally strong for a subject which, while not absolutely fundamental in the sense indicated above, is necessarily included in the studies of a university for regional or local reasons. If it is argued that the undergraduates might travel to another university for the necessary instruction, it may be replied that in most cases it would be inconvenient and expensive and not seldom impossible. Assuming that the subject is taught in the university, the arguments adduced above show conclusively that opportunities for research are indispensable. A possible alternative would be to bring a teacher from another university to give a course of instruction in it. This is a plan which, though it has been adopted with good results in some universities, is not always possible or desirable. One can picture a case, in economics for example, where investigations into local conditions are absolutely necessary for the proper development of the teaching of the subject, and no substitute can adequately replace it.

While we are sensible of the need for economy and the avoidance of all unnecessary overlapping in our universities, we are also sensible of the wonderful developments which have taken place in higher and specialised studies in the few decades during which the modern universities have come into being and attained some degree of maturity. It may well be said that " not since the monastic period of the twelfth century, or the scholastic revolution of the sixteenth, has England known an educational movement so rich in romance, in courage, in devotion, and in promise." This extraordinary expansion and development, which has changed the whole face of education in England, is one of self-development untrammelled by vexatious restrictions. The modern university has developed under the wing of the State; it can no more dispense with Government assistance than it can with its students or staff. But if it is to fulfil its rightful destiny it must retain its freedom to develop from within. By all means let there be co-operation and co-ordination among the various universities, just as there are within the university itself. But if, unhappily, any attempt to lop or prune activities, hitherto self-determined, were to succeed, the measure of its success would be the measure of the nation's loss.

\section{More Light on the Bantu Languages.}

A Comparative Study of the Bantu and Semi-Bantu Languages. By Sir Harry H. Johnston. Vol. 2. Pp. xii +544 . (Oxford: Clarendon Press, 1922.) $3 l .3 s$.

FTER numerous and vexatious delays, the second A volume of this monumental work has at last seen the light. It contains "an analysis and com- parison of the phonology and word-roots and a comparative examination of the syntax of the Bantu and Semi-Bantu languages, together with the conclusions to be derived from this evidence." In accordance with this plan we have, first, a review of the various groups of Bantu and Semi-Bantu languages, following the arrangement adapted in the first volume. (An alphabetical index of languages, by the bye, would greatly facilitate research, though the student is helped to a considerable extent by the table on pp. 2-I3. In vol. $\mathrm{I}$, those not gifted with a remarkable memory for numbers had to turn over the pages till they found the particular language required.)

The classification adopted is open to some objections in detail-as was almost inevitable in the circumstances: but one had hoped to see some outstanding inaccuracies corrected in vol. $2, e . g$. the treatment of the two distinct languages Lala and Lamba as one and the same. This, of course, is due to Madan, the only authority accessible when the vocabularies were prepared; but other sources of information have since become available. Again, there is some confusion (vol. r, p. 28I, vol. 2, p. 79) as to the languages entered under 70: Chopi, to adopt the ordinary orthography, is a distinct language from Tswa, and also, we believe, from Lenge, which, again, is not the same as Hlengwe. (See e.g. Junod's map in the "Grammaire Ronga." Sir Harry Johnston dissents from this writer's view, but it is supported by good recent authority.)

The paragraphs dealing with "Group T: the ZuluKafir languages" contain several points calling for discussion. It is surely by an oversight that the palatal click $(q c, q)$ is said to be "confined mainly to Zulu and Sesuto." It does not occur in Zulu, and only doubtfully in Xosa. (Bleek: "Vide Boyce-Davis, p. 4, where the $q c$ is probably intended to indicate this sound.") The fact that it is found in Sesuto is interesting, as showing that it was probably borrowed direct from Hottentots or Bushmen-not, as usually assumed, from the Zulus. The same paragraph contains a somewhat perplexing assertion: "In Zulu the employment of clicks instead of diminishing is extending, through the same spirit of tribal selfassertion as may be met with in the Basuto. Whenever a present-day Zulu or even a Kafir" (why "even," seeing that click-words are more numerous in Xosa than in Zulu ?) " wishes to coin a new word--and they are doing this on an immense scale-he nearly always introduces a click into it. ..."

It is difficult to check statements of this kind unless one is in constant touch with natives, but a rough test may be made by consulting the list of neologisms at the end of Colenso's Dictionary (edition of 1905 , pp. 72I-724). Among 236 words we find only three 